\title{
Maurice Barrès, Mes Cahiers
}

\section{Michela Gardini}

\section{(2) OpenEdition}

\section{Journals}

\section{Edizione digitale}

URL: https://journals.openedition.org/studifrancesi/4793

DOI: 10.4000/studifrancesi.4793

ISSN: 2421-5856

\section{Editore}

Rosenberg \& Sellier

\section{Edizione cartacea}

Data di pubblicazione: 1 avril 2012

ISSN: 0039-2944

\section{Notizia bibliografica digitale}

Michela Gardini, «Maurice Barrès, Mes Cahiers», Studi Francesi [Online], 166 (I | LVI) | 2012, online dal 30 novembre 2015, consultato il 19 novembre 2021. URL: http://journals.openedition.org/studifrancesi/ 4793 ; DOI: https://doi.org/10.4000/studifrancesi.4793

Questo documento è stato generato automaticamente il 19 novembre 2021.

\section{(c) (i) ()}

Studi Francesi è distribuita con Licenza Creative Commons Attribuzione - Non commerciale - Non opere derivate 4.0 Internazionale. 


\title{
Maurice Barrès, Mes Cahiers
}

\author{
Michela Gardini
}

\section{NOTIZIA}

MAURICE BARRÈs, Mes Cahiers, tome I, préface d'Antoine COMPAGNON, Sainte-Marguerite sur Mer, Éditions des Équateurs, 2010, pp. 679; tome II, préface de François BROCHE, SainteMarguerite sur Mer, Éditions des Équateurs, 2011, pp. 654.

1 I due tomi dei Cahiers, pubblicati dalle Éditions des Équateurs coprono i periodi da gennaio 1896 a novembre 1904 (i primi undici Cahiers contenuti nel primo tomo) e da novembre 1904 a giugno 1908 (dal dodicesimo al diciannovesimo Cahier, contenuti nel secondo tomo). Si presentano come edizioni molto curate e complete: il ricchissimo apparato di note è stato allestito dal figlio dello scrittore, Philippe Barrès, con la collaborazione, per entrambi i volumi, di François Broche. La prima caratteristica dei Cahiers risiede nel fatto che essi si presentano come frammenti, assolutamente eterocliti, sotto forma di aneddoti, riflessioni, appunti per conferenze e discorsi pubblici, progetti futuri, bozze di romanzi (La Musulmane courageuse, tomo II, pp.141-162, diventerà Un jardin sur l'Oronte). In prima istanza, nelle intenzioni dell'autore, essi dovevano costituire il materiale per Mes Mémoires, collocati, nella loro forma incompiuta, in apertura dei Cahiers per volontà della vedova e del figlio. Essi, quindi, non appaiono come un'opera rielaborata, bensì come la prima stesura di quelle future memorie che, tuttavia, iniziò a scrivere troppo tardi, qualche mese soltanto prima di morire. Di pagina in pagina, la sfera privata e quella pubblica sconfinano l'una nell'altra in una continua osmosi tra passione letteraria e passione politica: «Je désirais sentir ma vie sans contradictions - scrive Barrès in Mes Mémoires - ne pas être divisé [...]. Ma littérature et ma politique devaient se correspondre, se compléter, s'harmoniser puisque j'avais de l'une et de l'autre le même besoin spontané, puisque j'étais allé à l'une et à l'autre sans le vouloir, d'un élan fatal» (tomo I, pp. 56-57). Come li definisce Compagnon, Mes Cahiers assomigliano ad un "laboratorio", un "deposito" (v. tomo I, p.16) di pensieri, riflessioni, abbozzi, che non conosceranno mai una forma definitiva, e in questo risiede la differenza rispetto ad altri celebri diari, dai Goncourt a 
Gide, assumendo anche l'aspetto di una galleria di personaggi, in cui prendono voce le personalità che animavano la scena culturale e politica di quegli anni. Ma la struttura di fondo, il principio di coesione dei Cahiers sono dati, piuttosto, dalla vena malinconica che attraversa i due tomi e che trova nel tema della morte una delle sue massime esplicitazioni, dando voce al Barrès più intimo e introspettivo. L'autore scrive in occasione della morte dei genitori, del suicidio del suo rivale in politica Sautumier, al quale dedica pagine toccanti (secondo quaderno, tomo I, pp.98-101) e di altri personaggi. Il tema della morte si interseca, prepotentemente, con l'amore viscerale per la sua terra, la Lorena, di cui celebra, appunto, i morti, a cominciare da Giovanna D'Arco, un mito personale di Barrès che costella i quaderni sotto forma di appunti, conferenze e pensieri lirici.

2 Come auspica Compagnon, la pubblicazione dei Cahiers potrebbe essere l'occasione per ricominciare a leggere un autore a lungo proscritto per le sue idee politiche scioviniste, a partire dalla cruciale vicenda dell'affaire Dreyfus che vide Barrès schierato tra gli antidreyfusards. Ma proprio le pagine di Mes Cahiers rendono la problematica del nazionalismo più complessa ed intrecciata, innanzitutto, con esigenze di appartenenza, di riconoscibilità territoriale: «Pour nous Lorrains qu'est-ce qui fait notre patriotisme français? - scrive Barrès nel 1904 (undicesimo quaderno, tomo I, pp. 495-496) - La défense des droits de l'homme? Les institutions du Code civil? Les gloires militaires? Tout cela est contesté. Pour nous, la véritable unité franco-lorraine est faite de la défense de nos frontières par la France». Una rivendicazione di identità, di radicamento dalla quale, tuttavia, paradossalmente Barrès ha sentito, per tutta la vita, la necessità di allontanarsi, esiliandosi nell'inseguimento di terre lontane e immaginarie, come dimostra la sua passione per l'Oriente: «Je n'ai jamais cessé de désirer l'Orient», scrive Barrès nel sesto quaderno (tomo I, p. 314). La fascinazione esercitata dall'Oriente, infine, oltre ad offrire l'ispirazione per diversi romanzi, trova in questa sede la propria espressione anche nel Cahier d'Egypte, pubblicato all'interno del diciottesimo Cahier (tomo II, pp. 417-462). 